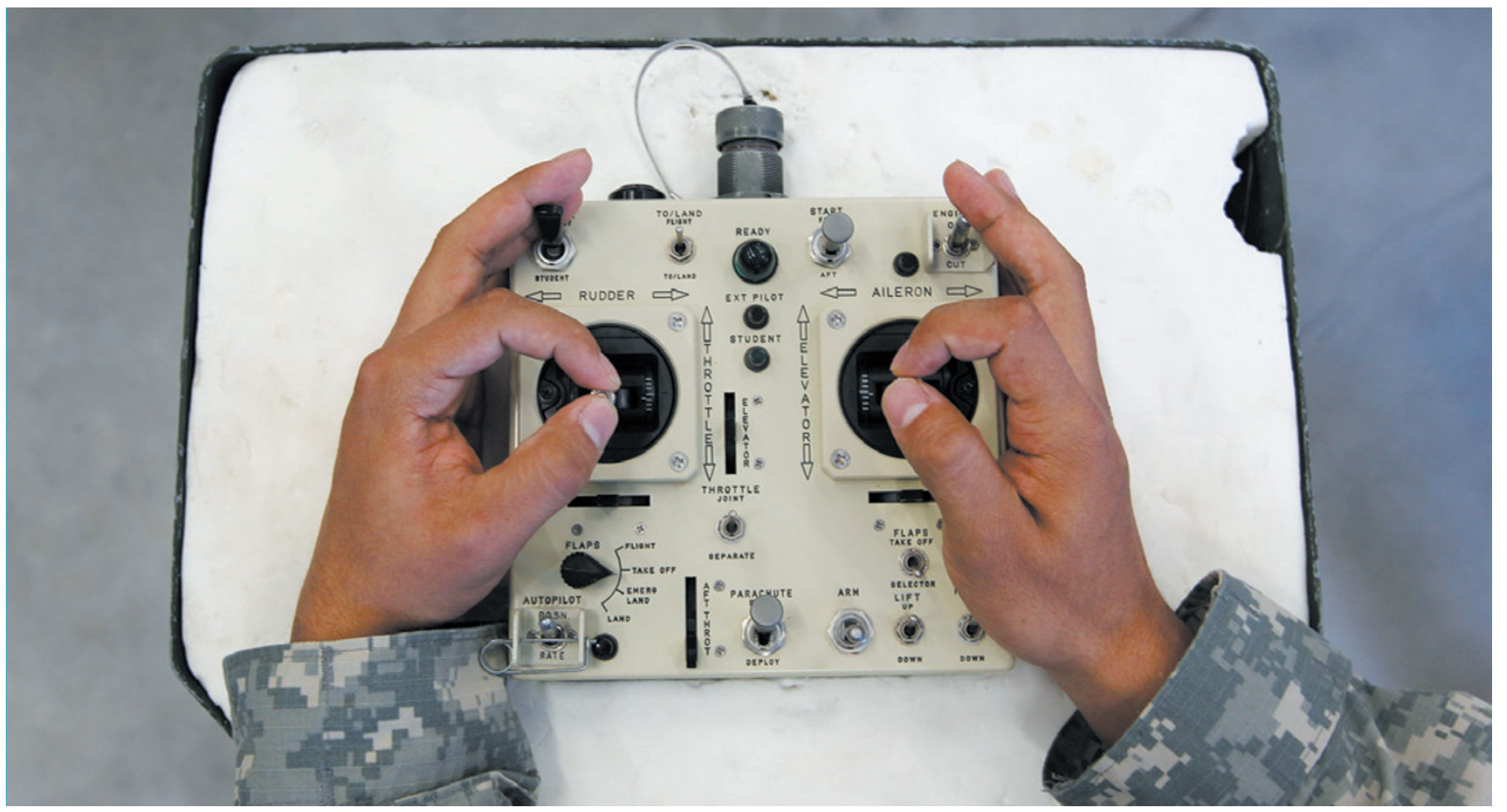

Remote control of drones is one of the many contributions science and technology have made to war.

\title{
The evolving science of war
}

\section{Sharon Weinberger assesses two studies probing the roles of physics and psychology in conflicts past, present and future.}

$\mathrm{B}$ arry Parker's chronicle of the interplay between the military and science, The Physics of War, is largely a record of people developing more effective ways to kill each other. So it is poignant that Parker, a physicist, begins the book with a passage on a battle that took place more than 3,000 years ago in what is now Syria, a country in the middle of a bloody civil war threatening to draw in world powers. It seems that fundamentals of warfare have not changed, but with the advent of science and the creation of morepowerful weapons, the stakes are now higher.

Physics, Parker argues, has enabled much of the killing. For thousands of years people have used its principles to build increasingly powerful weapons, even before they understood what made the devices work. Weapon by weapon, and in excruciating detail, Parker shows how a mix of tinkering, basic maths and physics - including, much later, nuclear physics - enabled the development of weapons of war, from the chariots of ancient Syria to modern thermonuclear weapons.

That is a lot of ground to cover, and Parker's book is best read as a primer for those interested in the science of weapons and their contributions to various battles. It is on less solid ground in helping us to understand when military leaders realized that advancing science as a discipline could aid warfare. At one point, for example, Parker writes that "Napoleon studied physics along with mathematics and astronomy in military school, and knew the importance of science to war". In the same paragraph, however, he states that there is "no indication" that Napoleon "took a lot of interest in physics, or science, in general".

By contrast, Michael Matthews' lively and engaging Head Strong makes the weighty argument that psychology is emerging as the science that will make the difference in twenty-first-century warfare. War is not just about killing, he argues; it is about understanding the enemy, and ourselves. Matthews, a military psychologist, makes a valiant case, noting how psychology has contributed to everything from selecting leaders to helping soldiers navigate foreign cultures. He predicts that it will one day help to produce drugs "capable of regulating the brain's response to combat stress", perhaps
The Physics of War: From Arrows to Atoms BARRY PARKER

Prometheus Books: 2014.

Head Strong: Psychology and Military

Dominance in the 21st Century

MICHAEL D. MATTHEWS

Oxford University Press: 2013.

eliminating post-traumatic stress disorder.

When Matthews writes about his own research on the psychology of soldier performance and leadership, or his experience as a professor at the United States Military Academy at West Point in New York, the book springs to life. He shows how psychological methods have challenged some of the military leadership's entrenched beliefs about gender, citing a study he was involved in that surveyed Air Force base commanders' attitudes about women. Almost every commander told a story of how the pilot of a crashed, burning aeroplane died because a female firefighter was not strong enough to carry him out. The story, Matthews later found, was apocryphal.

His larger point is how science, particularly psychology, can inform decisions about 
integration. In another example, he notes that West Point, which trains officers, targets women's enrolment at about 15\% to reflect the ratio of women in the military. That sounds noble; but he notes that West Point tries (and has so far failed) to recruit African Americans at a rate reflecting their representation in the recruiting-age population. Were the same rule applied to women, he writes, they should make up half the class. West Point spokesman Francis DeMaro declined to comment on goals linked to gender or ethnicity, instead providing numbers on the most recent entering class (16\% women, $10 \%$ African Americans) that seem to bolster Matthews's argument. "We strive to ensure our cadet population is representative of the soldiers they will lead," says DeMaro.

Matthews stumbles a bit when talking about the importance of psychology in understanding foreign cultures. $\mathrm{He}$ praises the Human Terrain System, the well-intentioned but troubled US programme that embeds social scientists into teams that deploy with the military (see Nature http://doi.org/bxmgsw; 2011). Matthews engages in the same kind of oversimplification of cultural knowledge that underlies the problems facing these teams. He recalls how a US military commander in Iraq learned that arriving heavily armed at meetings with community leaders was a "major social blunder" (as it might be, of course, in most cultures).

By focusing on the progression of weapons, Parker misses the point at which physics was overtaken by other fields, including psychology, as disciplines crucial to warfare. But Matthews, in focusing so closely on current and future applications of psychology, omits mention of one of most important military psychologists.

In the 1960s, the US Department of Defense's Advanced Research Projects Agency hired psychologist J. C. R. Licklider to create a behavioural sciences office. It was his unique insights into how man would interact with machine in the future that laid the foundation for ARPANET, the precursor to the Internet. Today, networked computers are as key to military command and control as they are to modern society. It could be argued that, thanks to Licklider, military psychology has already revolutionized war. Whether it will help the United States to win future wars is another matter.

Sharon Weinberger is a Global Fellow at the Woodrow Wilson International Center for Scholars in Washington DC. Her book about the Defense Advanced Research Projects Agency will be published in 2015. e-mail:sharonweinberger@gmail.com

\section{PSYCHOLOGY}

\section{Feeling the fear}

\section{David Adam applauds the autobiography of a high-flyer confronting his own nervous suffering head-on.}

$O^{\prime \prime}$ cott Stossel is, in his own words, a "quivering, quaking, neurotic wreck". He is frightened of flying, vomiting and cheese. He has thrown tennis matches from a winning position just to get off the exposed stage of the court, and struggles to control his bowels. For three decades he has been a regular in the offices and clinics of psychiatrists, psychologists and psychoanalysts, and a testing ground for whatever treatment, drug or quack therapy they thought might bring some relief.

Stossel is also a married father of two and editor of The Atlantic magazine. His terrific book My Age of Anxiety is his attempt to reconcile those two worlds, and offers an unsparing and unsentimental look at a subject that many keep hidden: mental illness.

Stossel suffers from anxiety, a condition that he identifies early on as tricky to define. Is anxiety the list of symptoms offered by psychiatrists? The biological response to threat that we share with animals? The social consequence of the shared knowledge of our mortality? Or the chemical consequence of misfiring neurotransmitters and brain circuitry?

Books exploring personal experiences of mental illness tend to be either overwrought accounts of personal trauma "Stosseloffers an that shed little light unsparing and on the world beyond unsentimental the author's nose, or look at asubject the more detached that many keep observations of hidden." scientists and medics. It is rare to find works that bridge these objectives, which is one reason that the writer Andrew Solomon achieved such success with The Noonday Demon (Chatto \& Windus, 2001), his personal and scientific account of depression. Stossel's book deserves a place on this higher shelf.

My Age of Anxiety covers all the academic ground one would expect. We get the biological idea that anxiety is an unsuited modern deployment of an atavistic fightor-flight physiological response to threat, the psychological basis for conditioned responses - that anxiety is a learned, if inappropriate, fear - and the nascent attempts to link mind and body through brain scans and genetics. With help from some friendly neuroscientists, Stossel finds he has a variant of the SERT gene implicated in anxiety.

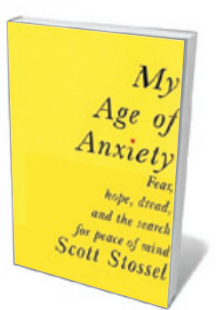

My Age of Anxiety: Fear, Hope, Dread, and the Search for Peace of Mind SCOTT STOSSE Knopf: 2014.
Stossel is also aware of current controversies in psychiatry. He gives fair voice, for example, to both sides in the debate over the usefulness of pharmaceuticals, talk therapies and the shift from viewing anxiety as a social and philosophical issue to a disorder of chemical and electrical signals.

And he shows his skills as a writer with colourful and moving accounts of traumatic personal episodes. As a child and adolescent he suffered extreme separation anxiety and, aged 13 , would wake the neighbours and ask them to call the police when his parents were out. The treatments were often equally grisly. Given an emetic syrup to make him vomit as exposure therapy to rid him of his phobia, he endures only hours of severe nausea and painful retching.

Stossel addresses the heterogeneous ingredients of anxiety by trying to cover them all - as if a sense of completeness alone can bind them together. His policy of full disclosure may not always be to everyone's tastes: an anecdote of a blocked toilet and a meeting with John F. Kennedy Jr, for one, feels gratuitous. But the approach also offers useful reminders of the human cost of taking strong positions on the use of drugs and other areas of scientific and medical uncertainty. Poised between a psychiatrist who puts him on drugs and a therapist who urges him to abandon them, Stossel finds himself lying to the therapist to spare her feelings when he returns to the psychiatrist.

One of Stossel's motives is the hope that the book might bring him peace. Still, he writes, "If it's relief from nervous suffering that I crave, then burrowing into the history and science of anxiety, and into my own psyche, is perhaps not the best way to achieve it."

We should all hope it works: the man is due a break.

David Adam is Nature's Editorial and Columns editor. His first book, The Man Who Couldn't Stop: OCD and the True Story of a Life Lost in Thought, will be published in April 2014. 